\title{
Do young adults value sustainable diet practices? Continuity in values from adolescence to adulthood and linkages to dietary behaviour
}

\author{
Nicole Larson*, Melissa N Laska and Dianne Neumark-Sztainer \\ Division of Epidemiology and Community Health, School of Public Health, University of Minnesota, Suite 300, 1300 \\ South Second Street, Minneapolis, MN 55454, USA
}

Submitted 5 July 2018: Final revision received 31 January 2019: Accepted 20 February 2019: First published online 6 June 2019

\begin{abstract}
Objective: To describe continuity over time in reports of valuing sustainable diet practices and investigate relationships between values, household meal behaviours and dietary intake.

Design: Observational study. Participant ratings of how important it is for food to be produced as organic, not processed, locally grown and not GM were categorized to represent whether they valued (very/somewhat important) or did not value (a little/not at all important) each practice. Diet quality markers (e.g. fruit servings) were based on an FFQ.

Setting: Mailed and online surveys.

Participants: Young adults ( $n$ 1620; 58 \% female, mean age 31 (SD 1.6) years) who were participating in Project EAT (Eating and Activity among Teens and Young Adults) and responded to follow-up surveys in 2003-2004 and 2015-2016.

Results: One-third (36.1\%) of participants reported valuing $<2$ practices at both assessments; 11.1 and $34.5 \%$ respectively reported valuing $\geq 2$ practices in 2003-2004 only and in 2015-2016 only; $18.3 \%$ reported valuing $\geq 2$ practices at both assessments. Regression models including demographics, parental status and vegetarian status showed that valuing $\geq 2$ practices was associated with preparation of meals with vegetables at least a few times/week, less frequent purchase of family meals from fast-food restaurants, and higher diet quality in 2015-2016. For example, those who valued $\geq 2$ practices consumed nearly one full vegetable serving more than other young adults on an average day and part of this difference was specifically associated with intake of dark green and red/orange vegetables. Conclusions: Addressing the sustainability of food choices as part of public health messaging may be relevant for many young adults.
\end{abstract}

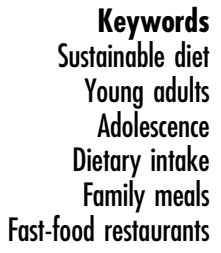

Sustainable diets have a minimal impact on the environment, contribute to food security, and promote a healthy life for present and future generations ${ }^{(1,2)}$. More specifically, the principles that define sustainable diets include optimizing natural and human resources along with being protective and respectful of biodiversity and ecosystems, culturally acceptable, accessible, economically fair and affordable, nutritionally adequate, safe and healthy ${ }^{(1)}$. Research focusing on selected aspects of sustainable diets (e.g. eating food that is organic, minimally processed, locally grown and not GM) has found evidence that individuals who are more aware of where and how food is produced tend to select more nutrient-dense food choices $^{(1,3,4)}$. For example, a prior population-based study of support for selected sustainable practices found that adolescents and emerging adults (15-23 years) in the Project EAT (Eating and Activity among Teens and Young Adults) cohort were more likely to consume a dietary pattern consistent with the US Healthy People 2010 Objectives if they valued two or more sustainable diet practices ${ }^{(5)}$. These findings from Project EAT and similar studies may be salient to the framing of public health messages and wellness programming, as sustainably produced food has become more widely available to consumers in recent decades ${ }^{(5-7)}$. However, little is known about the continuity over time of valuing sustainable diet practices and 
thus the extent that values formed in response to messaging may carry forward or have an impact on later food choices.

Consuming a nutrient-dense diet during the transition from adolescence into the young adult years (18-35 years) may protect against future chronic disease, promote optimal reproductive outcomes, support psychological resilience and help to prevent excess weight gain ${ }^{(8-16)}$. Although the importance of dietary intake quality during this life stage is well established, most young adults do not meet recommendations for healthy eating such as those within the Dietary Guidelines for Americans ${ }^{(17-19)}$. National survey data show that intakes of whole fruit, non-starchy vegetables and whole grains are lower than recommended, while nearly all US young adults exceed the recommended $\mathrm{Na}$ intake and maximum energy intake from added sugars and solid fats ${ }^{(9,17,20,21)}$. There is a strong need for research to inform the identification of relevant and effective nutrition education messaging for young adults and the optimal timing of message delivery. The development of educational messages and wellness programming for young adults could benefit from identification of population subgroups that may have other values related to their food, such as where their food comes from and the use of sustainable diet practices.

The current study was designed to inform preventive interventions by examining how trajectories of valuing sustainable diet practices are related to adult food choices among the Project EAT cohort. The first aim of the study was to describe continuity in values for a set of sustainable practices (eating food that is organic, minimally processed, locally grown and not GM) that were assessed twice over a decade of development, involving the transition from adolescence to young adulthood. In addition, the study aimed to examine associations between valuing sustainable practices and participant characteristics (i.e. sex, ethnicity/race, age, educational attainment, household income, parental status, vegetarian status). A third aim was to investigate cross-sectional and longitudinal relationships between values for sustainable practices and measures of dietary behaviour and intake. Specifically, the study examined household meal behaviours and markers of diet quality (e.g. fruit and vegetable consumption). It was hypothesized on the basis of prior research findings that valuing sustainable diet practices would be related to higher involvement in household food preparation and dietary quality ${ }^{(5)}$, but no hypotheses were made specifically regarding the continuity of values over time.

\section{Methods}

\section{Sample and study design}

Project EAT is a large, population-based cohort study of eating and weight-related outcomes that has followed young people from adolescence to adulthood. The original assessment was designed as a cross-sectional study of students enrolled at public middle schools and senior high schools in the Minneapolis-St. Paul metropolitan area of MN, USA, in 1998-1999(22,23). Trained research staff collected student survey data within health, physical education and science classrooms after parental consent procedures were completed in accordance with the requests of the participating school districts. In some schools, passive consent procedures were used, whereas in others, active consent procedures were required. Given growing research interest in the eating behaviours and weightrelated health of young people, a decision was made to follow up in 2003-2004 and at future time points with the participants who had completed surveys and provided sufficient contact information ${ }^{(24,25)}$. Additional details of the sampling frame and design have been published previously ${ }^{(5,22,23,26-29)}$.

Data for the analysis reported here were drawn from the follow-up survey conducted in 2003-2004 and the most recent follow-up survey in 2015-2016. In 2003-2004, current contact information was identified for 3672 of the original 4746 participants and 2516 complete surveys were returned in response to a mailed invitation (response rate: 68.4\%). In 2015-2016, follow-up EAT-IV survey invitations were again mailed to participants in the original 1998-1999 assessment but only to those who had responded to at least one previous follow-up survey wave. EAT-IV survey and FFQ data were collected online, by mail or by telephone from $66.1 \%$ of those for whom contact information was available at the time ( $n$ 2770), resulting in the completion of surveys by 1830 young adults with a mean age of 31.0 (SD 1.6) years ${ }^{(30-33)}$. Most respondents $(95.4 \%)$ completed the online survey and completers took an average of $40 \mathrm{~min}$ to answer the questions. More than $88 \%$ of the EAT-IV sample had also completed the mailed survey wave in 2003-2004 ( $n$ 1620, mean age 19.4 (SD 1.7) years) and formed the analytic sample for analyses reported here ${ }^{(24,28)}$.

All study protocols were approved by the University of Minnesota's Institutional Review Board Human Subjects Committee. Written assent from participants was obtained in 1998-1999. For the follow-up surveys, participants were mailed a consent form with their paper survey or reviewed a consent form as part of the online survey. Completion of a follow-up survey implied written consent.

\section{Survey development}

Measures relating to values for sustainable diet practices were first added to the Project EAT survey in 2003-2004 in response to focus group discussions with a separate sample of young people. The sample of young people who completed draft surveys as part of these focus groups were not part of the population-based cohort, but were recruited by posting fliers in the same Minneapolis-St. Paul metropolitan area and were similar in age to the cohort sample (n 20, aged 18-23 years) ${ }^{(5,34)}$. Focus group participants commented on the lack of measures regarding their values 
around how food is produced and distributed; based on the perception of this sample that values for sustainable diet practices was relevant to eating behaviours and dietary patterns, measures of these values were subsequently added to the cohort survey. Identical measures of values for sustainable diet practices were included on the 2015-2016 EAT-IV survey along with new topics (e.g. household food preparation) that were identified by another separate sample of thirty-five focus group participants who provided feedback on the age appropriateness of measures for adults entering their fourth decade of life ${ }^{(31)}$. The estimates of item test-retest reliability reported below were determined in a subgroup of 103 cohort participants who completed a draft survey twice within a period of $1-4$ weeks.

\section{Values for sustainable diet practices}

Values were assessed in 2003-2004 and 2015-2016 by asking participants to respond to four measures and rate, separately for each practice, 'How important is it to you that your food is ...?' 'produced as organic', 'not processed', 'locally grown' and 'not genetically modified ${ }^{\text {(5) }}$. Response options for each of the four measures were $1=$ 'not at all', $2=$ 'a little', $3=$ 'somewhat' and $4=$ 'very important'. The test-retest reliability for each individual practice was strong (test-retest $r=0.78-0.83$ ) and when ratings were summed to form an overall index of values for sustainable practices the Cronbach's $\alpha$ was $0 \cdot 83$. For all analyses described here, ratings were dichotomized to represent whether a participant valued ('somewhat' or 'very important') or did not value ('not at all' or 'a little') each practice. Overall value for sustainable diet practices was defined at each time point by whether or not an individual valued at least two practices.

\section{Housebold meal behaviours}

Meal preparation behaviour was assessed among all young adults who were not living alone and family meals were assessed among those who were living with child(ren) of their own in 2015-2016. Frequency of at-home meal preparation was determined by asking the question: 'During the past month, how often have you prepared a meal that included vegetables?'; the inclusion of vegetables was specified as an indicator of meal quality ${ }^{(35)}$. Six response categories were combined for analysis to represent infrequent ('never', 'one time', 'a few times', 'weekly') $v$. frequent ('a few times a week', 'most days of the week') preparation of a meal (test-retest agreement = $87 \%$ ). Frequency of eating family meals was assessed with the question: 'In the past week, how many times did all, or most, of the people living in your household eat a meal together?' Seven response categories were combined for analysis to represent $0-4$ times or $\geq 5$ times in a given week (test-retest agreement $=87 \%$ ). Frequency of purchasing fast food for family meals was assessed with the question: 'During the past week, how many times was a family meal purchased from a fast-food restaurant and eaten together either at the restaurant or at home? (pizza counts) $^{(36)}$. Four response categories were combined for analysis to represent $0-1$ purchases or $\geq 2$ purchases of fast food in a given week (test-retest agreement $=79 \%$ ).

\section{Dietary intake}

A semi-quantitative FFQ was administered at the same time as the EAT-IV survey in 2015-2016 to assess usual past-year intake of whole fruit (excluding juice), vegetables (excluding potatoes), whole grains and sugar-sweetened drinks ${ }^{(37)}$. In addition, the FFQ was used to assess usual daily intakes of total energy (kJ or kcal), added sugar (g), saturated fat (percentage of total energy), $\mathrm{Na}(\mathrm{mg})$ and $\mathrm{Ca}(\mathrm{mg})$. Dietary intake outcomes were selected based on identification as a dietary component of public health concern in the Dietary Guidelines for Americans, 2015-2020 ${ }^{(38)}$. A list of foods that were assessed on the FFQ and used to define each food category outcome is included in the footnotes of Table 3. Daily servings were defined in alignment with the quantities of foods and beverages listed on the FFQ; a serving was quantified as one-half cup for fruits and vegetables and $16 \mathrm{~g}$ for whole grains. For sugar-sweetened drinks, a serving was defined as the equivalent of one glass, bottle or can. Nutrient intake outcomes were based on an analysis of all foods included on the FFQ and determined in 2016 by the Nutrition Questionnaire Service Center at the Harvard School of Public Health. The nutrient analysis used a specially designed database, primarily based on the US Department of Agriculture's Nutrient Database for Standard Reference. Previous studies have examined and reported on the reliability and validity of intake estimates ${ }^{(37,39,40)}$. Responses to the FFQ were excluded if participants reported a biologically implausible level of total energy intake $(<2092 \mathrm{~kJ} / \mathrm{d}$ $(<500 \mathrm{kcal} / \mathrm{d})$ or $<20920 \mathrm{~kJ} / \mathrm{d}(>5000 \mathrm{kcal} / \mathrm{d}))$ or left twenty or more items blank.

\section{Participant characteristics}

Characteristics of participants were self-reported; sex and ethnicity/race were based on self-report on the original school-based survey in 1998-1999, whereas age, educational attainment, household income, parental status and vegetarian status were assessed in 2015-2016. Educational attainment was assessed with the question: 'What is the highest level of education that you have completed?' (test-retest agreement $=97 \%$ ) and the response options provided were 'middle school or junior high', 'some high school', 'high school graduate or GED' (where GED is General Equivalency Diploma), 'vocational, technical, trade or other certification programme', 'associate degree', 'bachelor degree', 'graduate or professional degree (MS, MBA, $\mathrm{MD}, \mathrm{PhD}$, etc.)' and 'other'. Household income was assessed with the question: 'What was the total income of your household before taxes in the past year?' (test-retest $r=0.94$ ) and the response options provided were 'less than \$US 20000 ', 
'\$US 20 000-34 999', '\$US 35 000-49 999', '\$US 50 000-74999', '\$US 75 000-99 999' and '\$US 100000 or more'. Parental status was based on report of living with one or more child of your own for the majority of the past year. Vegetarian status was based on self-identification (test-retest agreement $($ yes $/$ no $)=98 \%)$ with any type of vegetarian eating. Response categories for educational attainment and household income were collapsed for analysis based on the distribution of responses.

\section{Statistical analysis}

The first aim regarding continuity in values for sustainable diet practices was addressed among the full sample of participants who responded to both the 2003-2004 and 20152016 follow-up surveys. Descriptive statistics were calculated to examine values for each of the separate practices and an overall value for sustainable diet practices as defined by indicating two or more specific practices were somewhat or very important. Four value trajectory groups were further defined as: perceived lack of importance at both time points (never important), importance only in 2003-2004 (early importance), importance only in 2015-2016 (late importance) and importance at both time points (long-term importance). The percentage of the participants categorized within each trajectory group was calculated.

The second aim regarding associations between values for sustainable diet practices and participant characteristics was likewise addressed within the full analytic sample of 1620 cohort members. Frequencies and percentages were calculated to examine the distribution of values across characteristics identified by young adults. The $\chi^{2}$ test was additionally used to test unadjusted differences in values across characteristics.

The third aim regarding cross-sectional and longitudinal associations of overall values for sustainable diet practices with household meal behaviours and dietary intake was examined using regression models. Models of dietary intake used the sub-sample of cohort respondents who had completed an FFQ in 2015-2016 ( $n$ 1396). A dichotomous indicator of overall values for sustainable practices (important, not important) was based on whether or not $\geq 2$ practices were rated as 'somewhat' or 'very important' in 2015-2016 and was the independent variable for crosssectional models. Categorical trajectory group was the independent variable (never, early, late, long-term importance) for longitudinal models. Regression models were adjusted for identified demographic correlates (sex, ethnicity/race, age, educational attainment), parental status and vegetarian status on the basis of prior research ${ }^{(5,41,42)}$. Missing data were handled using listwise deletion; however, less than $5 \%$ of cases were dropped from the models. Interpretation of the model results for each dietary intake outcome focused on least square means in absolute dietary intake or intake per $4184 \mathrm{~kJ}$ (1000 kcal); model results for household meal behaviours were interpreted using adjusted prevalence estimates.
All analyses were conducted using the statistical software package SAS version 9.3 (2011) and weighted because attrition from the original school-based sample did not occur at random. The data were weighted using the response propensity method ${ }^{(43)}$. Response propensities (i.e. the probability of responding to the surveys in 2003-2004 and 20152016) were estimated using a logistic regression of responses on a large number of predictor variables from the original school-based survey. The weighting method resulted in estimates for the analytic sample ( $n$ 1620) that were representative of the demographic make-up of the original school-based sample (see online supplementary material, Supplemental Table S1), thereby allowing results to be more fully generalizable to the school-based sample of young people who completed baseline surveys in 1998-1999. A 95\% confidence level was used to interpret the statistical significance of probability tests.

\section{Results}

\section{Changes over time in values for sustainable diet practices}

Among the cohort members who completed a survey at both time points in 2003-2004 and 2015-2016 ( $n$ 1620), the proportion who indicated a sustainable diet practice was not important at both time points ranged from $34.0 \%$ for not processed to $52.9 \%$ for organic (Table 1 ). The groups indicating that a practice was important only in 2003-2004 and not later in the life course (early importance) were small, ranging from $8.1 \%$ of the cohort for organic to $15.3 \%$ for not GM. Conversely, those who indicated a practice was important only in 2015-2016 and not earlier during adolescence or emerging adulthood (late importance) ranged from $26.9 \%$ for organic to $37.0 \%$ for not processed. The proportion of the cohort indicating the importance of a specific practice at both time points (long-term importance) ranged from $11.4 \%$ for locally grown to $17.7 \%$ for not processed and not GM.

Valuing two or more practices, used here to identify overall value for sustainable diet practices, was variable over time. Approximately one-third (36.1\%) of the cohort indicated lack of importance at both time points (never important), $11.1 \%$ reported early importance, $34.5 \%$ reported late importance and $18.3 \%$ reported long-term importance.

\section{Associations of participant characteristics with values for sustainable diet practices}

The percentage of the 1620 young adults (aged 25-36 years) who indicated in 2015-2016 that it was somewhat or very important for their food to be produced according to a specific practice ranged from $38.9 \%$ for organic to $54.3 \%$ for not processed (Table 2). Just over half $(52.9 \%)$ of these young adults reported valuing two or more practices by indicating their importance. 
Table 1 Trajectories of values for sustainable nutrition practices among young people who participated in the 2003-2004 and 2015-2016 Project EAT surveys as members of the cohort enrolled at public schools in Minneapolis-St. Paul, MN, USA in 1998-1999 ( $n$ 1620* ${ }^{\star}+$

\begin{tabular}{|c|c|c|c|c|}
\hline & $\begin{array}{c}\text { Never important } \\
(\%)\end{array}$ & $\begin{array}{c}\text { Early importance } \\
\text { (only in 2003-2004) } \\
(\%)\end{array}$ & $\begin{array}{c}\text { Late importance } \\
\text { (only in 2015-2016) } \\
(\%)\end{array}$ & $\begin{array}{c}\text { Long-term importance } \\
\text { (in 2003-2004 \& } \\
2015-2016) \\
(\%)\end{array}$ \\
\hline Organic & 52.9 & $8 \cdot 1$ & $26 \cdot 9$ & $12 \cdot 1$ \\
\hline Not processed & 34.0 & $11 \cdot 3$ & $37 \cdot 0$ & $17 \cdot 7$ \\
\hline Locally grown & $49 \cdot 4$ & $8 \cdot 3$ & $30 \cdot 9$ & $11 \cdot 4$ \\
\hline Not GM & $35 \cdot 5$ & $15 \cdot 3$ & 31.5 & $17 \cdot 7$ \\
\hline$\geq 2$ practices & $36 \cdot 1$ & $11 \cdot 1$ & 34.5 & $18 \cdot 3$ \\
\hline
\end{tabular}

Project EAT, Project Eating and Activity among Teens and Young Adults.

*All percentages are weighted to reflect the probability of responding to the follow-up Project EAT surveys in 2003-2004 and 2015-2016.

†The four value trajectory groups were defined by indicating the practice was 'not at all' or only 'a little' important at both time points (never important), 'somewhat' or 'very important' only in 2003-2004 (early importance), 'somewhat' or 'very important' only in 2015-2016 (late importance) and 'somewhat' or 'very important' at both time points (long-term importance)

The proportion of young adults who valued two or more sustainable practices was highest among participants who identified as female $(P<0.001)$ and those who reported following a vegetarian eating pattern $(P<0.001)$ in 20152016. Similar associations with respect to sex and vegetarian status were observed for each of the four separate practices shown in Table 2. Additionally, the percentages of young adults who indicated the importance of organic and the importance of not processed food were highest among those who had completed more years of formal education by the time of the 2015-2016 survey (organic, $P=0.007$; not processed, $P<0.001$ ). Ethnic/racial identity, originally reported by participants in 1998-1999, was associated with the perceived importance of just two of the sustainable diet practices (both $P<0.001$ ), such that value for locally grown foods was lowest among White and African-American participants and value for non-GM foods was lowest among White participants.

\section{Cross-sectional associations of value for sustainable diet practices with dietary behaviours and intake in adulthood}

Among the sub-sample of 1396 young adults who completed an FFQ in 2015-2016, overall value for sustainable diet practices was associated with the percentage who reported preparing meals with vegetables more than once per week (mean difference: $6.9 \%, P<0.001$ ), the percentage who reported purchasing family meals from fast-food restaurants on fewer than two occasions per week (mean difference: $11.1 \%, P=0.002$ ) and multiple markers of higher diet quality in young adulthood (Table 3 ). Specifically, young adults who valued sustainable practices had higher intakes of several nutrient-dense foods, including whole fruit $(P<0.001)$, total vegetables other than potatoes $(P<0.001)$, dark green vegetables $(P<0.001)$, red and orange vegetables $(P<0.001)$ and whole grains $(P=0 \cdot 021)$. Young adults who valued sustainable practices also had lower intakes of sugar-sweetened drinks $(P<0.001)$, added sugar $(P<0.001)$ and saturated fat $(P=0.012)$. Observed mean differences in daily dietary intake were most pronounced for whole fruit and total vegetables; for example, those who indicated an overall value for sustainable practices consumed nearly one full vegetable serving more than other young adults on an average day and part of this difference was specifically associated with a combined average of a daily half serving more of vegetables from the dark green and red/orange subgroups. Less substantial mean differences (e.g. 0.2 servings of whole grains, -0.3 servings of sugar-sweetened drinks, $-0.3 \%$ of energy from saturated fat) were observed for other dietary markers when average intakes of those who indicated an overall value for sustainable practices were compared with others who did not; however, all observed associations remained statistically significant in additional models that adjusted for energy intake. Mean energy-adjusted $\mathrm{Na}$ intake was also found to be lower among those who indicated an overall value for sustainable practices compared with others who did not report this value (important $=1042 \mathrm{mg} \mathrm{Na} / 4184 \mathrm{~kJ}(1000 \mathrm{kcal})$, not important $=1078 \mathrm{mg} \mathrm{Na} / 4184 \mathrm{~kJ}(1000 \mathrm{kcal}), P=0.004)$.

\section{Longitudinal associations of value for sustainable diet practices with bousehold meal behaviours and dietary intake in adulthood}

Among the same sub-sample of 1396 young adults, further analysis showed that overall value for sustainable diet practices during late adolescence or emerging adulthood in 2003-2004 was mostly not related to young adults' dietary intake in 2015-2016 unless the value was carried into adulthood (Table 4). Results showed that dietary behaviours and intake were similarly better (e.g. more fruits/vegetables and whole grains, less fast-food restaurant purchases and sugarsweetened drinks) among young adults who reported late importance of sustainable practices and those who reported long-term importance in comparison to the behaviours and intake of those who indicated sustainable practices were never important or of early importance in 2003-2004 only. Likewise, for most dietary markers, reported intake was similar among young adults who indicated sustainable practices were never important and those who indicated early 
Table 2 Percentages of young adults ( $n$ 1620), by sociodemographic characteristics, who reported it was 'somewhat' or 'very important' that their food is produced according to sustainable nutrition practices in the 2015-2016 Project EAT survey*

\begin{tabular}{|c|c|c|c|c|c|c|}
\hline & $n$ & Organic (\%) & Not processed (\%) & Locally grown (\%) & Not GM (\%) & $\geq 2$ practices $(\%)$ \\
\hline Overall & 1620 & 38.9 & $54 \cdot 3$ & $42 \cdot 6$ & $49 \cdot 1$ & $52 \cdot 9$ \\
\hline \multicolumn{7}{|l|}{ Sex } \\
\hline Male & 681 & $35 \cdot 4$ & $49 \cdot 7$ & $36 \cdot 0$ & $41 \cdot 6$ & 47.4 \\
\hline Female & 939 & $42 \cdot 6$ & $59 \cdot 0$ & $49 \cdot 4$ & $57 \cdot 0$ & $58 \cdot 7$ \\
\hline$P$ value $\dagger$ & & 0.003 & $<0.001$ & $<0.001$ & $<0.001$ & $<0.001$ \\
\hline \multicolumn{7}{|l|}{ Race } \\
\hline White & 1118 & $37 \cdot 4$ & $54 \cdot 6$ & $40 \cdot 1$ & $44 \cdot 3$ & $51 \cdot 2$ \\
\hline African American & 134 & $36 \cdot 1$ & $56 \cdot 8$ & $36 \cdot 5$ & $56 \cdot 1$ & $53 \cdot 3$ \\
\hline Asian & 231 & $44 \cdot 8$ & $53 \cdot 3$ & $47 \cdot 0$ & $50 \cdot 9$ & 54.5 \\
\hline Other & 123 & $38 \cdot 2$ & $51 \cdot 0$ & $52 \cdot 0$ & $55 \cdot 2$ & $54 \cdot 8$ \\
\hline$P$ value & & $0 \cdot 101$ & 0.599 & $<0.001$ & $<0.001$ & 0.683 \\
\hline \multicolumn{7}{|l|}{ Age group } \\
\hline 25-29 years & 392 & 39.5 & $53 \cdot 5$ & $44 \cdot 1$ & $43 \cdot 1$ & $50 \cdot 0$ \\
\hline 30-36 years & 1228 & $38 \cdot 7$ & 54.5 & $42 \cdot 0$ & $51 \cdot 3$ & $54 \cdot 0$ \\
\hline$P$ value $\dagger$ & & 0.792 & 0.709 & 0.445 & 0.004 & 0.160 \\
\hline \multicolumn{7}{|l|}{ Education } \\
\hline High school & 343 & 35.7 & $46 \cdot 8$ & $44 \cdot 0$ & $46 \cdot 0$ & $49 \cdot 1$ \\
\hline 2-year post-secondary & 388 & 34.4 & $49 \cdot 1$ & $41 \cdot 7$ & 53.4 & 51.9 \\
\hline 4-year post-secondary & 596 & $41 \cdot 8$ & $59 \cdot 8$ & $38 \cdot 2$ & $48 \cdot 0$ & $53 \cdot 4$ \\
\hline Graduate/professional & 283 & $46 \cdot 2$ & $66 \cdot 9$ & $47 \cdot 6$ & $46 \cdot 4$ & $59 \cdot 4$ \\
\hline$P$ value & & 0.007 & $<0.001$ & 0.098 & 0.131 & 0.094 \\
\hline \multicolumn{7}{|l|}{ Household income } \\
\hline$<\$ U S 20000$ & 112 & $35 \cdot 4$ & $44 \cdot 6$ & $42 \cdot 2$ & $45 \cdot 5$ & 52.5 \\
\hline \$US $20000-<50000$ & 447 & $41 \cdot 8$ & $53 \cdot 8$ & $47 \cdot 5$ & $52 \cdot 3$ & $55 \cdot 1$ \\
\hline$\$$ US $50000-<75000$ & 359 & $32 \cdot 8$ & 55.4 & $41 \cdot 1$ & $52 \cdot 9$ & 52.5 \\
\hline$\geq \$ U S 75000$ & 676 & $41 \cdot 2$ & $56 \cdot 7$ & $38 \cdot 1$ & $44 \cdot 6$ & $51 \cdot 7$ \\
\hline$P$ value & & 0.026 & 0.057 & 0.018 & 0.029 & 0.717 \\
\hline \multicolumn{7}{|l|}{ Parental status } \\
\hline No children & 762 & $42 \cdot 9$ & $57 \cdot 8$ & $42 \cdot 1$ & 47.5 & $54 \cdot 7$ \\
\hline One or more child & 780 & 34.3 & 50.5 & $42 \cdot 8$ & $50 \cdot 3$ & $51 \cdot 3$ \\
\hline$P$ value $\dagger$ & & 0.001 & 0.005 & 0.796 & 0.281 & 0.188 \\
\hline \multicolumn{7}{|l|}{ Vegetarian status } \\
\hline Non-vegetarian & 1558 & 38.0 & 53.9 & $42 \cdot 1$ & $48 \cdot 6$ & $52 \cdot 3$ \\
\hline Vegetarian & 61 & $71 \cdot 0$ & $71 \cdot 0$ & $61 \cdot 4$ & $68 \cdot 8$ & $75 \cdot 9$ \\
\hline$P$ value & & $<0.001$ & 0.025 & 0.008 & 0.006 & 0.001 \\
\hline
\end{tabular}

Project EAT, Project Eating and Activity among Teens and Young Adults.

*All percentages are weighted to reflect the probability of responding to follow-up surveys in 2003-2004 and 2015-2016; sample numbers reflect the unweighted size of the participant group. The subgroup sample numbers for each characteristic do not all add to 1620 due to missing responses.

$\dagger P$ values represent testing for independence of sociodemographic categorization and value for a sustainable practice by the $\chi^{2}$ test.

importance. For example, the percentage of young adults who prepared a meal with vegetables more than once per week was $78.1 \%$ among those for whom sustainable practices were never important and similarly $83.5 \%$ among those who reported early importance. Young adults who indicated that sustainable practices were never important or reported early importance in adolescence or emerging adulthood had comparable mean whole fruit intakes of approximately one serving per day (never important $=1.2$ servings $v$. early importance $=1.3$ servings, $P=0 \cdot 110$ ). Intake of sugarsweetened drinks was an exception to this pattern; young adults who indicated the early importance of sustainable practices had somewhat lower mean intake in comparison to those who indicated sustainable practices were never important (never important $=0.8$ servings $v$. early importance $=0.6$ servings, $P=0.02$ ).

\section{Discussion}

The present study described value for sustainable diet practices among a population-based sample of young adults and investigated relationships between valuing sustainable practices and measures of household meal behaviours and dietary intake. Results from the 2015-2016 survey showed that each of the practices (organic, not processed, locally grown, not GM) was valued by more than a third of young adults (25-36 years) and more than half of young adults valued two or more practices. Values for each specific practice and overall value for sustainable practices (as indicated by valuing two or more practices) were found to track modestly over time. Additionally, support was found for the hypothesis that valuing sustainable diet practices is related to more frequent preparation of meals with vegetables, fewer purchases from fast-food restaurants and markers of better dietary quality.

An overall value for sustainable diet practices was widely held by young adult members of the populationbased sample enrolled in Project EAT. It is thus likely that addressing the environmental sustainability of food choices as part of public health messaging to promote healthy dietary behaviours would be received as relevant by many young adults, including nutritionally vulnerable groups 
Table 3 Adjusted prevalence of dietary behaviours and daily dietary intakes, with their standard errors, by young adult report of an overall value for sustainable diet practices ( $\geq 2$ practices were 'somewhat' or 'very important') in the 2015-2016 Project EAT survey*,$\dagger$

\begin{tabular}{|c|c|c|c|c|c|}
\hline & \multicolumn{2}{|c|}{ Not important } & \multicolumn{2}{|c|}{ Important } & \multirow[b]{2}{*}{$P$ value } \\
\hline & Mean & SE & Mean & SE & \\
\hline \multicolumn{6}{|l|}{ Household meal behaviours } \\
\hline Prepare meal more than once/week (\%) & $78 \cdot 1$ & 4.5 & $85 \cdot 0$ & $3 \cdot 2$ & $<0.001$ \\
\hline Have family meal $\geq 5$ times/week (\%) & $63 \cdot 6$ & $9 \cdot 3$ & $63 \cdot 1$ & 9.2 & 0.879 \\
\hline $\begin{array}{l}\text { Purchases from fast-food restaurant for } \\
\text { family meals }>2 \text { times/week }(\%)\end{array}$ & $44 \cdot 0$ & $9 \cdot 1$ & $32 \cdot 9$ & $8 \cdot 1$ & 0.002 \\
\hline \multicolumn{6}{|l|}{ Dietary intakef } \\
\hline \multicolumn{6}{|l|}{ Fruits and vegetables (servings/d) } \\
\hline Whole fruit (no juice) & $1 \cdot 2$ & 0.06 & 1.9 & 0.06 & $<0.001$ \\
\hline Vegetables (no potatoes) & $2 \cdot \overline{3}$ & 0.09 & $3 \cdot 2$ & 0.08 & $<0.001$ \\
\hline Dark green vegetables & 0.5 & 0.03 & 0.8 & 0.03 & $<0.001$ \\
\hline Red and orange vegetables & 0.4 & 0.02 & 0.7 & 0.02 & $<0.001$ \\
\hline Whole grains (servings/d) & $2 \cdot 1$ & 0.08 & $2 \cdot 3$ & 0.07 & 0.021 \\
\hline Sugar-sweetened drinks (servings/d) & 0.7 & 0.03 & 0.4 & 0.03 & $<0.001$ \\
\hline Added sugar $(\mathrm{g} / \mathrm{d})$ & $63 \cdot 2$ & 1.6 & 52.5 & 1.5 & $<0.001$ \\
\hline $\mathrm{Na}(\mathrm{mg} / \mathrm{d}) \S$ & 2135 & 40 & 2084 & 38 & 0.333 \\
\hline Saturated fat (\% of total daily energy) & $11 \cdot 1$ & 0.09 & $10 \cdot 8$ & 0.09 & 0.012 \\
\hline $\mathrm{Ca}(\mathrm{mg} / \mathrm{d})$ & 1032 & 23 & 1083 & 22 & 0.086 \\
\hline
\end{tabular}

Project EAT, Project Eating and Activity among Teens and Young Adults.

*Models included sex, ethnicity/race, educational attainment, age group, parental status and vegetarian status as covariates.

tThe sample was limited to participants who completed surveys in both 2003-2004 and 2015-2016 as well as an FFQ in 2015-2016 ( $n$ 1396). The sample size for analysis of meal behaviours was further restricted as a result of skip patterns in the survey. Meal preparation frequency was reported only by participants who did not live alone ( $n 1150)$ and family meal behaviours were reported only by participants who were parents ( $n$ 666).

$\ddagger$ Whole fruit servings were defined by reported intake of raisins/grapes, prunes/dried plums, bananas, cantaloupe, fresh apples/pears, oranges, grapefruit, strawberries, blueberries, peaches/plums and apricots. Dark green vegetable servings were defined by reported intake of broccoli, kale/mustard greens/chard, spinach (cooked, raw) and romaine/leaf lettuce. Red and orange vegetable servings were defined by intake of tomatoes, tomato/spaghetti sauce, tomato juice, carrots (cooked, raw), yams/sweet potatoes and dark orange (winter) squash. Total vegetable servings included intake of all dark green, red and orange vegetables along with intake of string beans, beans/lentils, peas/lima beans, cauliflower, corn, mixed/stir-fry vegetables, eggplant/zucchini/other squash, iceberg/head lettuce, celery and onions. Whole grain servings were defined by grams of whole grains ( 1 serving $=16 \mathrm{~g}$ ) coming from cereals, breads, crackers, rice, popcorn and other grain foods. Sugar-sweetened drink servings were defined by reported intake of carbonated beverages with caffeine and sugar, other carbonated beverages with sugar, and other sugared beverages such as lemonade and sports drinks. $\S$ Model showed statistically significant differences $(P=0.004)$ between young adults who indicated sustainable practices were important $v$. not important when adjusted for energy intake using the density method (i.e. modelled as $\mathrm{mg} \mathrm{Na} / 4184 \mathrm{~kJ}$ (1000 kcal) daily total energy).

such as those who identify with an ethnic/racial minority background and those who have a low-income household $^{(44)}$. Evaluation of such messaging will, however, be important to ensure it has a positive and equitable impact, and to identify the need for message tailoring as the literature on the patterning of values for sustainable diet practices among various population subgroups of young adults is mixed. While our results aligned with other studies in finding women, vegetarians and individuals with higher formal educational attainment tend to more often value some sustainable diet practices ${ }^{(5,45,46)}$, aspects of the results reported here do not align with patterns reported by the Organic Trade Association and other studies ${ }^{(42,47)}$. For example, the observation that fewer parents than nonparents valued organic practices was in contrast to findings of the 2017 US Families' Organic Attitudes and Behaviors Study and other research that has found becoming a parent is related to a stronger affinity for organic ${ }^{(42,47)}$. If parents are receptive to messages about sustainable diets, then tailoring related healthy eating messages to them as a group may be especially useful to encourage more preparation of meals at home and less purchasing of food from fast-food restaurants for family meals.
Results of the current study also align with and extend previous research that has examined how valuing sustainable diet practices may be related to dietary behaviour and quality. The present study confirmed the relevancy for young adults of earlier findings from Project EAT that showed adolescents and emerging adults who value sustainable practices tend to consume diets of higher nutritional quality ${ }^{(5)}$. The findings reported here suggest that valuing sustainable practices is likewise related to better dietary intake and more frequent at-home meal preparation following the transition to adulthood, which typically involves greater responsibility in managing meals for oneself and often for other household members. Further, it was determined that the nutritional benefits associated with valuing sustainable practices earlier in development were not carried forward unless a value for sustainable practices was also carried into adulthood. These findings are unique in that most other research studies regarding linkages between dietary intake and environmental sustainability have focused on the climate impact (i.e. greenhouse gas emissions) associated with recommended dietary patterns $^{(1,48)}$. Collectively the existing literature suggests that young adults who value sustainable diet practices are more 
Table 4 Adjusted prevalence of dietary behaviours and mean daily dietary intakes, with their standard errors, by continuity of overall value for sustainable diet practices ( $\geq 2$ practices were 'somewhat' or 'very important') from adolescence or emerging adulthood (2003-2004) to young adulthood (2015-2016) reported in the 2015-2016 Project EAT survey ${ }^{\star}, \dagger$

\begin{tabular}{|c|c|c|c|c|c|c|c|c|c|}
\hline & \multicolumn{2}{|c|}{$\begin{array}{l}\text { Never important } \\
\quad(\text { (n 544) }\end{array}$} & \multicolumn{2}{|c|}{$\begin{array}{c}\text { Early importance } \\
\text { (only in 2003- } \\
2004) \\
(n 114)\end{array}$} & \multicolumn{2}{|c|}{$\begin{array}{l}\text { Late importance } \\
\text { (only in 2015- } \\
2016) \\
(n 499)\end{array}$} & \multicolumn{2}{|c|}{$\begin{array}{c}\text { Long-term } \\
\text { importance } \\
\text { (in 2003-2004 \& } \\
2015-2016) \\
(n 239)\end{array}$} & \multirow[b]{2}{*}{$P$ value } \\
\hline & Mean & SE & Mean & SE & Mean & SE & Mean & SE & \\
\hline \multicolumn{10}{|l|}{ Household meal behaviours } \\
\hline Prepare meal more than once/week (\%) & $78 \cdot 1^{\mathrm{a}}$ & $5 \cdot 1$ & $83 \cdot 5^{\mathrm{a}, \mathrm{b}}$ & $4 \cdot 7$ & $86 \cdot 1^{\mathrm{b}}$ & $3 \cdot 6$ & $88.0^{\mathrm{b}}$ & 3.4 & 0.001 \\
\hline Have family meal $\geq 5$ times/week (\%) & $75 \cdot 2$ & $13 \cdot 3$ & $69 \cdot 0$ & $15 \cdot 9$ & $78 \cdot 8$ & $12 \cdot 0$ & $67 \cdot 8$ & $15 \cdot 7$ & 0.138 \\
\hline $\begin{array}{l}\text { Purchases from fast-food restaurant for } \\
\text { family meals } \geq 2 \text { times/week (\%) }\end{array}$ & $58 \cdot 1^{a}$ & $10 \cdot 3$ & $47 \cdot 7^{\mathrm{a}, \mathrm{b}}$ & $11 \cdot 6$ & $47 \cdot 6^{\mathrm{b}}$ & $10 \cdot 7$ & $42 \cdot 6^{\mathrm{b}}$ & $10 \cdot 6$ & 0.049 \\
\hline \multicolumn{10}{|l|}{ Dietary intakeł } \\
\hline \multicolumn{10}{|l|}{ Fruit and vegetable (servings/d) } \\
\hline Whole fruit (no juice) & $1 \cdot 2^{\mathrm{a}}$ & 0.07 & $1 \cdot 3^{\mathrm{a}}$ & 0.14 & $1.9^{b}$ & 0.08 & $1.9^{b}$ & 0.11 & $<0.001$ \\
\hline Vegetables (no potatoes) & $2 \cdot 3^{a}$ & $0 \cdot 10$ & $2 \cdot 3^{a}$ & 0.19 & $3 \cdot 1^{\mathrm{b}}$ & $0 \cdot 10$ & $3 \cdot 5^{\mathrm{c}}$ & 0.14 & $<0.001$ \\
\hline Dark green vegetables & $0.5^{\mathrm{a}}$ & 0.04 & $0.5^{\mathrm{a}}$ & 0.07 & $0.8^{\mathrm{b}}$ & 0.04 & $0.9^{c}$ & 0.05 & $<0.001$ \\
\hline Red and orange vegetables & $0.4^{\mathrm{a}}$ & 0.02 & $0.5^{\mathrm{a}}$ & 0.04 & $0 \cdot 6^{b}$ & 0.02 & $0.7^{\mathrm{c}}$ & 0.03 & $<0.001$ \\
\hline Whole grains (servings/d) & $2 \cdot 0^{\mathrm{a}}$ & 0.09 & $2 \cdot 2^{a, b, c}$ & 0.17 & $2 \cdot 3^{\mathrm{b}, \mathrm{c}}$ & 0.09 & $2 \cdot 3^{\mathrm{c}}$ & 0.13 & 0.026 \\
\hline Sugar-sweetened drinks (servings/d) & $0.8^{\mathrm{a}}$ & 0.04 & $0 \cdot 6^{\mathrm{b}}$ & 0.07 & $0.4^{\mathrm{c}}$ & 0.04 & $0.4^{\mathrm{c}}$ & 0.06 & $<0.001$ \\
\hline Added sugar $(\mathrm{g} / \mathrm{d})$ & $62 \cdot 6^{a}$ & 1.9 & $63 \cdot 5^{\mathrm{a}}$ & 3.6 & $50 \cdot 4^{b}$ & $2 \cdot 0$ & $51 \cdot 2^{b}$ & $2 \cdot 8$ & $<0.001$ \\
\hline $\mathrm{Na}(\mathrm{mg} / \mathrm{d}) \S$ & 2101 & 46 & 2210 & 84 & 2064 & 46 & 2098 & 65 & 0.559 \\
\hline Saturated fat (\% of total daily energy) & $11 \cdot 2^{\mathrm{a}}$ & 0.11 & $11 \cdot 1^{\mathrm{a}, \mathrm{b}}$ & 0.21 & $10 \cdot 7^{\mathrm{b}}$ & 0.11 & $10 \cdot 9^{\mathrm{a}, \mathrm{b}}$ & 0.16 & 0.020 \\
\hline $\mathrm{Ca}(\mathrm{mg} / \mathrm{d})$ & 1031 & 27 & 1033 & 49 & 1075 & 27 & 1098 & 38 & 0.302 \\
\hline
\end{tabular}

Project EAT, Project Eating and Activity among Teens and Young Adults.

a,b,c Mean values within a row with unlike superscript letters were significantly different $(P<0.05)$.

${ }^{*}$ Models included sex, ethnicity/race, educational attainment, age group, parental status and vegetarian status as covariates. The independent variable was represented as four trajectory groups defined by indicating the practice was 'not at all' or only 'a little' important at both time points (never important), important only in $2003-2004$ (early importance), important only in 2015-2016 (late importance) and important at both time points (long-term importance).

tThe overall sample was limited to participants who completed survey items regarding sustainable practices in both 2003-2004 and 2015-2016, and also completed an FFQ in 2015-2016 ( $n$ 1396). The sample size for analysis of meal behaviours was further restricted as a result of skip patterns in the survey. Meal preparation frequency was reported only by participants who did not live alone $(n 1150)$ and family meal behaviours were reported only by participants who were parents $(n 666)$.

‡Details of the foods included within each food group are detailed in Table 3 .

$\S$ Model showed statistically significant differences $(P=0.014)$ across trajectory categories when adjusted for energy intake using the density method (i.e. modelled as mg Na/ $4184 \mathrm{~kJ}$ (1000 kcal) daily total energy).

likely to report markers of dietary patterns that promote health and have a less negative impact on the environment than the average US $\operatorname{diet}^{(1,48)}$.

Of relevance to interpreting the reported study results, there are certain strengths and limitations that are important to consider. Strengths included the large and populationbased sample, longitudinal aspects of the design, attention to multiple markers of dietary quality and the combined attention on various sustainable practices. The focus of the analysis on adults in their 20 s and 30 s is unique and noteworthy given the dietary behaviours of parents within this population group may also have a secondary impact on the intake of their children ${ }^{(49)}$. The diversity of the sample with respect to income/education and life situations also provided an important opportunity to build understanding of values for sustainable practices among population subgroups. However, associations with dietary behaviours and intake were not tested within subgroups and some caution should be used in generalizing the results to populations outside the Midwest given that all participants were originally recruited in the Minneapolis-St. Paul metropolitan area. Although sampling weights were used to correct for attrition, it is also possible that some bias remained after accounting for the finding that young people who completed the follow-up surveys were more likely to identify as female, White and having higher educational attainment. Additionally, some care should be used in interpreting reports of at-home meal preparation and support for sustainable practices given the brief nature of the questions and the potential for self-report bias. The assessment of at-home meal preparation frequency specified the inclusion of vegetables and thus likely captured mostly the preparation of evening meals. Survey items did not actually assess if participants make food purchases in line with their reports of valuing sustainable practices or whether valuing a given practice applied to all or more specifically to certain categories of foods. As no information on valuing sustainable practices was collected as part of the original school-based survey or follow-up survey in 2008-2009 ${ }^{(50)}$, it was not possible to examine how often values may fluctuate from adolescence to adulthood.

\section{Conclusions}

In conclusion, the results of the current study extend scientific evidence for addressing values around 
sustainable diet practices as part of dietary counselling and health promotion programming. The observation of widespread values for sustainable practices in combination with the finding that values often shift over time (e.g. $73 \%$ of young adults who valued purchasing locally grown foods in 2015-2016 did not similarly value this practice in 20032004) suggests it may be helpful for health professionals to routinely ask about values for sustainable practices when providing dietary advice. As individual values around sustainable diet practices and the values of their household members may have an impact on shopping patterns, food budgeting and meal planning, strategies for following dietary advice may need to be accordingly tailored. It would thus further be helpful for future studies to investigate how values for sustainable diet practices may be related to the diagnosis of a diet-related chronic disease or the advice of a health professional to lose weight. Likewise, intervention studies could evaluate whether it may be fruitful to address sustainable diet practices as part of public health messaging and health promotion programming designed to promote nutrient-dense food choices. For example, the feasibility and motivational impact of having young adults visit a farm or other food producer to learn about sustainable practices could be evaluated as part of workplace wellness programming. Similarly, future research could evaluate the potential benefits of providing education on sustainable practices as part of the Farmer's Market Voucher programmes for young adults enrolled in the Special Supplemental Nutrition Program for Women, Infants, and Children or the Supplemental Nutrition Assistance Program ${ }^{(51-53)}$. Little research to date has explored the impact of addressing sustainable values as part of wellness programming or nutrition education for adults.

In addition to the need for evaluation efforts, the results reported here suggest it may be worthwhile to further explore the perceptions of young adults regarding how their values regarding sustainable diet practices influence shopping habits and eating behaviours. Specifically, it could be particularly useful for qualitative studies of this nature to assess how values regarding sustainable diet practices influence behaviour among young adults with varied household incomes and cultural backgrounds. The current study identified some differences across population subgroups in the prevalence of holding a value for specific practices and accordingly the influence of valuing sustainable practices on dietary behaviour and intake may also vary. If access plays an important role, then it would further be relevant to gather ideas regarding how to make sustainably produced foods more accessible to young adults from lower-income households. Additionally, given that many young adults are parents, it would be potentially useful to explore how parents relay and transmit values regarding sustainable diet practices to their children.

\section{Acknowledgements}

Financial support: This work was supported by the National Heart, Lung, and Blood Institute (Principal Investigator: D.N.-S., grant number R01HL116892). Additional salary support was also provided by the National Heart, Lung, and Blood Institute (Principal Investigator: D.N.-S., grant number R35HL139853). The content is solely the responsibility of the authors and does not necessarily represent the official views of the National Heart, Lung, and Blood Institute or the National Institutes of Health. The National Heart, Lung, and Blood Institute and the National Institutes of Health had no role in the design, analysis or writing of this article. Conflict of interest: None. Authorship: N.L. conducted the statistical analysis and drafted the manuscript. M.N.L. helped to conceptualize the analysis plan. D.N.-S. conceptualized the larger Project EAT study design and oversaw data collection. All authors contributed to the interpretation of results and manuscript revisions. Ethics of buman subject participation: This study was conducted according to the guidelines laid down in the Declaration of Helsinki and all procedures involving human subjects were approved by the University of Minnesota's Institutional Review Board Human Subjects Committee. Informed consent was provided by all subjects.

\section{Supplementary material}

To view supplementary material for this article, please visit https://doi.org/10.1017/S136898001900096X

\section{References}

1. Auestad N \& Fulgoni V (2015) What current literature tells us about sustainable diets: emerging research linking dietary patterns, environmental sustainability, and economics. $A d v$ Nutr 6, 19-36.

2. Rose D, Heller M \& Roberto C (2019) Position of the Society for Nutrition Education and Behavior: the importance of including environmental sustainability in dietary guidance. J Nutr Educ Behav 51, 3-15.

3. von Koerber K, Bader N \& Leitzmann C (2017) Wholesome nutrition: an example of a sustainable diet. Proc Nutr Soc 76, 34-41.

4. Burlingame B \& Dernini S (2012) Sustainable diets and biodiversity: directions and solutions for policy, research and action. http://www.fao.org/policy-support/resources/ resources-details/en/c/522860/ (accessed January 2019).

5. Robinson-O'Brien R, Larson N, Neumark-Sztainer D et al. (2009) Characteristics and dietary patterns of adolescents who value eating locally grown, organic, nongenetically engineered, and non-processed food. J Nutr Educ Behav 41, 11-18.

6. Organic Trade Association (2017) Organic industry survey. https://www.ota.com/resources/organic-industry-survey (accessed June 2018). 
7. Pelletier J, Laska M, Neumark-Sztainer D et al. (2013) Positive attitudes toward organic, local, and sustainable foods are associated with higher dietary quality among young adults. J Acad Nutr Diet 113, 127-132.

8. VanKim NA, Larson N \& Laska MN (2012) Emerging adulthood: a critical age for preventing excess weight gain? Adolesc Med State Art Rev 23, 571-588.

9. 2015 Dietary Guidelines Advisory Committee (2015) Scientific report of the 2015 Dietary Guidelines Advisory Committee. http://health.gov/dietaryguidelines/2015scientific-report/ (accessed January 2019).

10. Hu T, Jacobs D, Larson N et al. (2016) Higher diet quality in adolescence and dietary improvements are related to less weight gain during the transition from adolescence to adulthood. J Pediatr 178, 188-193.

11. Buijsse B, Jacobs D, Steffen L et al. (2015) Plasma ascorbic acid, a priori diet quality score, and incident hypertension: a prospective cohort study. PLoS One 10, e01449920.

12. Steffen L, Van Horn L, Daviglus M et al. (2014) A modified Mediterranean diet score is associated with a lower risk of incident metabolic syndrome over 25 years among young adults: the CARDIA (Coronary Artery Risk Development in Young Adults) study. BrJ Nutr 112, 1654-1661.

13. Gresham E, Collins C, Mishra G et al. (2016) Diet quality before or during pregnancy and the relationship with pregnancy and birth outcomes: the Australian Longitudinal Study on Women's Health. Public Health Nutr 19, 2975-2983.

14. Wrobleski M, Parker E, Hurley K et al. (2018) Comparison of the HEI and HEI-2010 diet quality measures in association with chronic disease risk among low-income, African American urban youth in Baltimore, Maryland. J Am Coll Nutr 37, 201-208

15. Lutz L, Gaffney-Stomberg E, Williams K et al. (2017) Adherence to the Dietary Guidelines for Americans is associated with psychological resilience in young adults: a cross-sectional study. J Acad Nutr Diet 117, 396-403.

16. Xiao R, Simas T, Person S et al. (2015) Diet quality and history of gestational diabetes mellitus among childbearing women, United States, 2007-2010. Prev Chronic Dis 12, E25.

17. Krebs-Smith S, Guenther P, Subar A et al. (2010) Americans do not meet federal dietary recommendations. J Nutr $\mathbf{1 4 0}$, 1832-1838.

18. Larson N, Fulkerson J, Story M et al. (2013) Shared meals among young adults are associated with better diet quality and predicted by family meal patterns during adolescence. Public Health Nutr 16, 883-893.

19. Lipsky L, Nansel T, Haynie D et al. (2017) Diet quality of US adolescents during the transition to adulthood: changes and predictors. Am J Clin Nutr 105, 1424-1434.

20. Jackson S, King S, Zhao L et al. (2016) Prevalence of excess sodium intake in the United States - NHANES, 2009-2012. MMWR Morb Mortal Wkly Rep 64, 1393-1397.

21. Bailey R, Fulgoni V, Cowan A et al. (2018) Sources of added sugars in young children, adolescents, and adults with low and high intakes of added sugars. Nutrients 10, E102.

22. Neumark-Sztainer D, Story M, Hannan P et al. (2002) Overweight status and eating patterns among adolescents: where do youth stand in comparison to the Healthy People 2010 Objectives? Am J Public Health 92, 844-851.

23. Neumark-Sztainer D, Croll J, Story M et al. (2002) Ethnic/ racial differences in weight-related concerns and behaviors among adolescent girls and boys: findings from Project EAT. J Psychosom Res 53, 963-974.

24. Neumark-Sztainer D, Wall M, Eisenberg ME et al. (2006) Overweight status and weight control behaviors in adolescents: longitudinal and secular trends from 1999 to 2004. Prev Med 43, 52-59.

25. Larson N, Neumark-Sztainer D, Hannan P et al. (2007) Trends in fruit and vegetable consumption, 1999-2004: Project EAT. Am J Prev Med 32, 147-150.
26. Neumark-Sztainer D, Larson N, Fulkerson J et al. (2010) Family meals and adolescents: what have we learned from Project EAT (Eating Among Teens)? Public Health Nutr 13, $1113-1121$.

27. Larson N, Neumark-Sztainer D, Harnack L et al. (2008) Fruit and vegetable intake correlates during the transition to young adulthood. Am J Prev Med 35, 33-37.

28. Neumark-Sztainer D, Wall M, Guo J et al. (2006) Obesity, disordered eating, and eating disorders in a longitudinal study of adolescents: how do dieters fare 5 years later? J Am Diet Assoc 106, 559-568.

29. Neumark-Sztainer D, Wall M, Haines J et al. (2007) Why does dieting predict weight gain in adolescents? Findings from Project EAT-II: a 5-year longitudinal study. J Am Diet Assoc 107, 448-455.

30. Christoph M, Larson N, Laska M et al. (2018) Nutrition facts panels: who uses them, what do they use, and how does use relate to dietary intake? J Acad Nutr Diet 118, 217-228.

31. Larson N, Haynos A, Roberto C et al. (2018) Calorie labels on the restaurant menu: Is the use of weight-control behaviors related to ordering decisions? J Acad Nutr Diet 118, 399-409.

32. Neumark-Sztainer D, Wall M, Chen C et al. (2018) Eating, activity, and weight-related problems from adolescence to adulthood. Am J Prev Med 55, 133-141.

33. Larson N, Chen Y, Wall M et al. (2018) Personal, behavioral, and environmental predictors of healthy weight maintenance during the transition to adulthood. Prev Med 113, 80-90.

34. Larson N, Nelson M, Neumark-Sztainer D et al. (2009) Making time for meals: meal structure and associations with dietary intake in young adults. J Am Diet Assoc 109, 72-79.

35. Laska M, Larson N, Neumark-Sztainer D et al. (2012) Does involvement in food preparation track from adolescence to young adulthood and is it associated with better dietary quality? Findings from a 10-year longitudinal study. Public Health Nutr 15, 1150-1158.

36. Boutelle K, Fulkerson J, Neumark-Sztainer D et al. (2007) Fast food for family meals: relationships with parent and adolescent food intake, home food environment and weight status. Public Health Nutr 10, 16-23.

37. Rimm E, Giovannucci E, Stampfer M et al. (1992) Reproducibility and validity of an expanded selfadministered semiquantitative food frequency questionnaire among male health professionals. Am J Epidemiol 135, 1114-1126.

38. US Department of Agriculture \& US Department of Health and Human Services (2016) Dietary Guidelines for Americans 2015-2020, eighth edition. http://health.gov/ dietaryguidelines/2015/guidelines/ (accessed January 2019).

39. Feskanich D, Rimm E, Giovannucci E et al. (1993) Reproducibility and validity of food intake measurements from a semiquantitative food frequency questionnaire. J Am Diet Assoc 93, 790-796.

40. Yuan C, Spiegelman D, Rimm E et al. (2017) Validity of a dietary questionnaire assessed by comparison with multiple weighed dietary records or 24-hour recalls. Am J Epidemiol 185, 570-584.

41. Berge J, Larson N, Bauer K et al. (2011) Are parents of young children practicing healthy nutrition and physical activity behaviors? Pediatrics 127, 881-887.

42. Organic Trade Association (2017) Today's millennial: tomorrow's organic parent. https://ota.com/news/press-releases/ 19828 (accessed June 2018).

43. Little R (1986) Survey nonresponse adjustments for estimates of means. Int Stat Rev 54, 139-157.

44. Kirkpatrick S, Dodd K, Reedy J et al. (2012) Income and race/ ethnicity are associated with adherence to food-based dietary guidance among US adults and children. I Acad Nutr Diet 112, 624-635. 
45. Curl C, Beresford S, Hajat A et al. (2013) Associations of organic produce consumption with socioeconomic status and the local food environment: Multi-Ethnic Study of Atherosclerosis (MESA). PLoS One 8, e69778.

46. Bellows A, Alcaraz V \& Hallman W (2010) Gender and food, a study of attitudes in the USA towards organic, local, US grown, and GM-free foods. Appetite 55, 540-550.

47. Forman J, Silverstein J, Committee on Nutrition et al. (2012) Organic foods: health and environmental advantages and disadvantages. Pediatrics 130, e1406-e1415.

48. Nelson M, Hamm M, Hu F et al. (2016) Alignment of healthy dietary patterns and environmental sustainability: a systematic review. Adv Nutr 7, 1005-1025.

49. Nguyen B \& Powell L (2014) The impact of restaurant consumption among US adults: effects on energy and nutrient intakes. Public Health Nutr 17, 2445-2452.
50. Larson N, Neumark-Sztainer D, Story $\mathrm{M}$ et al. (2011) Identifying correlates of young adults' weight behavior: survey development. Am J Health Behav 35, 712-725.

51. US Department of Agriculture, Food and Nutrition Service (2019) WIC Farmers' Market Nutrition Program (FMNP). https://www.fns.usda.gov/fmnp/wic-farmers-market-nutritionprogram-fmnp (accessed January 2019).

52. Freedman D, Vaudrin N, Schneider C et al. (2016) Systematic review of factors influencing farmers' market use overall and among low-income populations. J Acad Nutr Diet 116 $1136-1155$.

53. US Department of Agriculture Food and Nutrition Service (2019) SNAP and farmers markets. https://snaped.fns. usda.gov/nutrition-education/nutrition-education-materials/ farmers-markets (accessed January 2019). 